\title{
Oncological outcomes of salvage cryotherapy after primary radiation therapy vs. primary cryotherapy: 10-year experience at a large Canadian referral center
}

\author{
Alexandra Bain ${ }^{1}$; Adam Kinnaird ${ }^{1}$; Ryan McLarty ${ }^{1}$; Gerald Todd ${ }^{1}$; Michael P. Chetner ${ }^{1}$; \\ Ambikaipakan Senthilselvan² \\ ${ }^{1}$ Division of Urology, Department of Surgery, University of Alberta, Edmonton, AB, Canada; ${ }^{2}$ School of Public \\ Health, University of Alberta, Edmonton, AB, Canada
}

Cite as: Can Urol Assoc J 2020 June 5; Epub ahead of print. http://dx.doi.org/10.5489/cuaj.6244

Published online June 5, 2020

$* * *$

\begin{abstract}
Introduction: Salvage cryotherapy is a guideline-recommended treatment of localized prostate cancer recurrence after radiation therapy. There is little published evidence analyzing the outcomes of salvage cryotherapy for recurrent prostate cancer following different primary therapy energy modalities.
\end{abstract}

Methods: We performed a retrospective analysis of patients who received whole gland salvage cryotherapy from 2007-2017 at a large tertiary referral center after either primary radiation therapy (RT) or primary whole gland cryotherapy. Primary outcome was biochemical failure, defined as per the Phoenix criteria (prostate-specific antigen [PSA] nadir $+2.0 \mathrm{ng} / \mathrm{ml}$ ).

Secondary outcomes included time to biochemical failure and development of metastatic disease. Results: Fifty-eight out of 391 patients who received cryotherapy were identified as having received salvage cryotherapy (after $\mathrm{RT}, \mathrm{n}=37$; after primary cryotherapy, $\mathrm{n}=21$ ). Biochemical recurrence occurred in $21(57 \%)$ patients with previous RT and in $17(81 \%)$ patients with previous cryotherapy $(\mathrm{p}=0.001)$. Median time to biochemical recurrence was 18 months for patients with previous RT and 13 months for patients with previous cryotherapy $(p=0.002)$. The biochemical free survival rate for primary radiation therapy patients was $71 \%$ at two years compared to $23 \%$ at two years for patients who underwent primary cryotherapy $(\mathrm{p}<0.01)$. There was no difference in the development of metastatic disease between groups (19\% vs. 18\%, cryo vs. radiation, $\mathrm{p}=0.34$ ).

Conclusions: These results suggest that salvage cryotherapy may offer more durable oncological control to patients after radiation compared to primary cryotherapy with a lower rate and longer duration before biochemical recurrence. 


\section{Introduction}

Prostate cancer is the most common non-cutaneous cancer in men, with an average of one in seven being diagnosed in their lifetime ${ }^{1}$. Variable rates of prostate cancer recurrence have been reported, ranging from $10-50 \%{ }^{1-3}$. Risk of local recurrence is dependent on multiple factors including initial Gleason Grade, clinical stage, preoperative PSA, and PSA nadir following primary therapy ${ }^{3-4}$.

Salvage cryotherapy is a guideline recommended treatment option in the treatment of recurrent localized disease ${ }^{5}$. Complication rates have decreased in conjunction with more favourable outcomes as the cryounits have been improved and re-modeled over time ${ }^{6-7}$. There is sufficient evidence demonstrating outcomes of salvage cryotherapy following primary radiation with a durable biochemical free survival achieved in approximately one-third of patients ${ }^{4,8}$. However, there is little evidence analyzing the outcomes of salvage cryotherapy for recurrent prostate cancer comparing different primary therapy modalities.

In this retrospective analysis at a large tertiary referral center, we aimed to compare oncological control of patients receiving salvage cryotherapy following either primary radiation therapy or primary cryotherapy.

\section{Methods}

A retrospective analysis was performed on all patients who received whole gland cryotherapy through the Northern Alberta Urology Clinic between 2007 to 2017. De-identified data was extracted from our electronic health record. Ethical approval was obtained from the Health Research Ethics Board of Alberta (project ID: HREBA.CC-17-0550).

Patients were included if they underwent cryotherapy in the setting of previous primary localized prostate cancer treatment (primary cryotherapy or radiotherapy). Baseline patient characteristics including age, Charlson comorbidity index (CCI $)^{9}$, BMI, PSA, PSA doubling time, clinical stage, pre-salvage biopsy Gleason score, prostate size, number of cores positive, and extent of disease were collected. The primary outcome was biochemical failure, defined by the Phoenix criteria of PSA nadir $+2.0 \mathrm{ng} / \mathrm{ml}$. Secondary outcomes included time to biochemical failure and development of metastatic disease.

Demographic data was analyzed using two-independent sample t-test or Fisher's exact test where appropriate. Kaplan-Meier survival analysis was conducted to compare differences in biochemical free survival between groups. Cox's proportional hazard regression was performed to examine the factors independently associated with biochemical free survival rates.

\section{Results}

391 patients underwent cryotherapy between 2007-2017, with 58/391 (15\%) having received salvage cryotherapy. Of these $21 / 58(36 \%)$ received primary cryotherapy and $37 / 58(64 \%)$ received primary radiation therapy (33 external beam and 4 brachytherapy) (Table 1). All patients had a repeat prostate biopsy which confirmed prostate cancer recurrence. Patients who received primary cryotherapy were older (70.8 vs 67.2, $\mathrm{p}=0.03)$ and had a faster PSA doubling 
time ( 8.5 vs 17.1 months, $p=0.002)$ compared to the primary radiotherapy group. There were no differences in pre-salvage PSA, clinical stage, Gleason grade, CCI, prostate size, or usage of adjuvant androgen deprivation therapy (Table 1). Neither radiation dose in the primary radiotherapy group nor testosterone levels of patients on ADT were available.

Overall complication rate was $27 \%$ for the primary radiotherapy group and $29 \%$ for the primary cryotherapy group (Table 2), with a total of 5 patients classified as Clavien Grade $3 \mathrm{~b}$ or greater (4 radiotherapy, 1 primary cryotherapy).

Biochemical recurrence (BCR) occurred more often in patients who previously received cryotherapy $(81 \%)$ versus primary radiotherapy $(57 \%)(p=0.001)$. Median time to BCR was shorter in patients who had received primary cryotherapy (13 vs. 18 months, $p=0.002$ ) (Table 2). The biochemical free survival rate for primary radiotherapy patients was $71 \%$ at two years compared to $23 \%$ for patients who underwent primary cryotherapy $(\mathrm{p}<0.01)$ (Figure 1$)$.

Using Cox proportional hazard regression to control for differences in age and presalvage PSA doubling time, the patients who received primary cryotherapy were at 2.4 times greater risk of developing BCR (hazard ratio (HR): 2.4, CI 1.1 - 5.4, p=0.03) (Table 3). There was no significant difference in the rate of metastatic progression between patients who received primary cryotherapy versus primary radiotherapy $(19 \%$ vs. $18 \% \mathrm{p}=0.34)($ Table 2$)$.

\section{Discussion}

This is one of the first studies evaluating prognostic outcomes of patients undergoing salvage cryotherapy after primary cryotherapy. These results suggest that salvage cryotherapy may offer better local oncological control to patients after radiation therapy compared to primary cryotherapy, with a lower overall rate of biochemical failure and a longer duration without recurrence.

Our documented rates of biochemical recurrence in both patient groups are higher than recent studies published ${ }^{8,10}$ and reasons for this are likely multifactorial including potentially more aggressive recurrent disease within our patient population and lack of standardized adjuvant ADT regime. When comparing results of the primary cryotherapy group to similar studies, our patient population still demonstrates higher GG scores and PSA nadir levels on average. Our rate of complications is equivalent to those observed across similar studies with rates between $15-25 \%{ }^{8}$.

The significant difference in PSA doubling time between the patient groups may infer a bias on our overall results - the primary cryotherapy group potentially had more aggressive disease thereby affecting both the incidence and time to BCR reported. Despite this bias, this analysis is significant as it allows us to better determine which patients are ideal candidates for salvage cryotherapy for local disease recurrence. The difference in biochemical failure rates may also be due to either tumour characteristics, or unidentified intrinsic technical limitations that are encountered when using the same treatment modality twice, as opposed to using two separate treatment techniques. 
GG and PSA nadir have been shown to be significant predictors of biochemical free survival post-salvage cryotherapy ${ }^{3}$. The median PSA nadir was lower in patients having previously received RT than in those with previous cryotherapy ( 0.3 vs $2.0 ; \mathrm{p}=0.044)$. This correlates with our lower biochemical free survival rate in the primary cryotherapy group.

Limitations of our study include its retrospective design and lack of assessment of quality-of-life metrics, in addition to lack of access to pre-salvage patient characteristics including testosterone levels and radiation doses.

\section{Conclusions}

Patients who received salvage cryotherapy following primary radiation therapy had a lower overall rate of biochemical failure and a longer duration without recurrence, demonstrating that salvage cryotherapy may offer more durable oncological control when treating recurrent prostate cancer post-radiation therapy. This data will allow for improved counselling for patients regarding management of their recurrent prostatic disease.

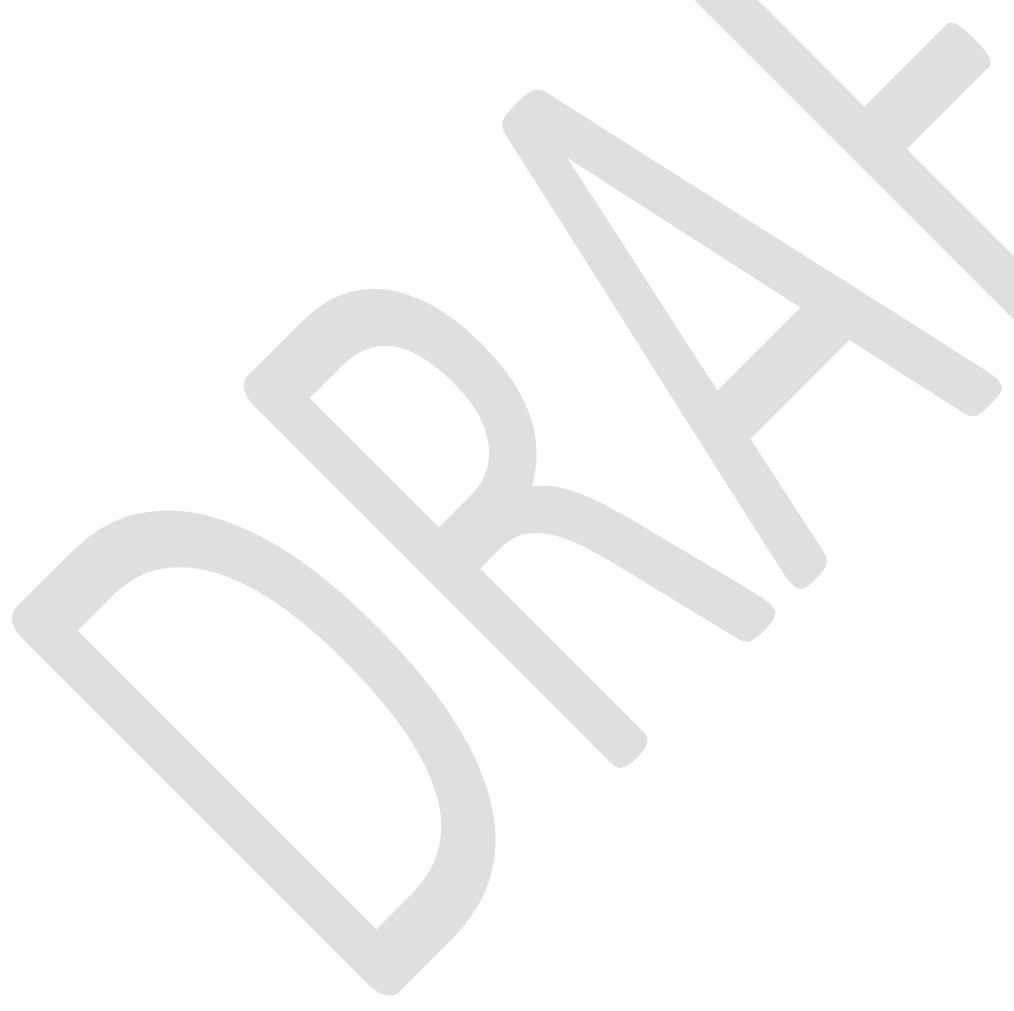




\section{References}

1. Fradet Y, Klotz L, Trachtenburg J, et al. The burden of prostate cancer in Canada. Can Urol Assoc J 2009;3:S92-100.

2. Finley DS, Belldegrum AS. Salvage cryotherapy for radiation-recurrent prostate cancer: Outcomes and complications. Curr Urol Rep 2011;12:209-15.

3. Spiess PE, Levy DA, Mouraviev V, et al. Predictors of biochemical failure in patients undergoing prostate whole-gland salvage cryotherapy: A novel risk stratification model. BJU Int 2013;112:E256-61.

4. Mouraviev V, Spiess PE, Stephen Jones J. Salvage cryoablation for locally recurrent prostate cancer following primary radiotherapy. Eur Urol 2012;61:1204-11.

5. National Comprehensive Cancer Network. NCCN guidelines version 4.2019 prostate cancer. NCCN Guidelines 2019; v4.2019, 08/19/19.

6. Parekh A, Graham PL, Nguyen PL. Cancer control and complications of salvage local therapy after failure of radiotherapy for prostate cancer: A systematic review. Semin Radiat Oncol 2013;23:222-34.

7. Langenhuijsen JF, Broers EM, Vergunst H. Cryosurgery for prostate cancer: An update on clinical results of modern cryotechnology. Eur Urol 2009;55:76-86.

8. Mustafa M, Delacroix S, Ward J, et al. The feasibility and safety of repeat cryosurgical ablation of localized prostate cancer. World J Surg Oncol 2015; 13: 340.

9. Charlson ME, Pompei P, Ales KL, et al. A new method of classifying prognostic comorbidity in longitudinal studies: Development and validation. J Chronic Dis 1987;40:373-83.

10. Wenske S, Quarrier S, Katz AE. Salvage cryosurgery of the prostate after primary radiotherapy or cryosurgery: long-term clinical, functional, and oncologic outcomes in a large cohort at a tertiary referral centre. Eur Urol 2013; 64; 1-7. 


\section{Figures and Tables}

Fig. 1. Kaplan-Meier estimate of biochemical recurrence-free survival for patients undergoing salvage cryotherapy following primary radiotherapy vs. primary cryotherapy $(\mathrm{p}<0.01 ; \log$-rank).

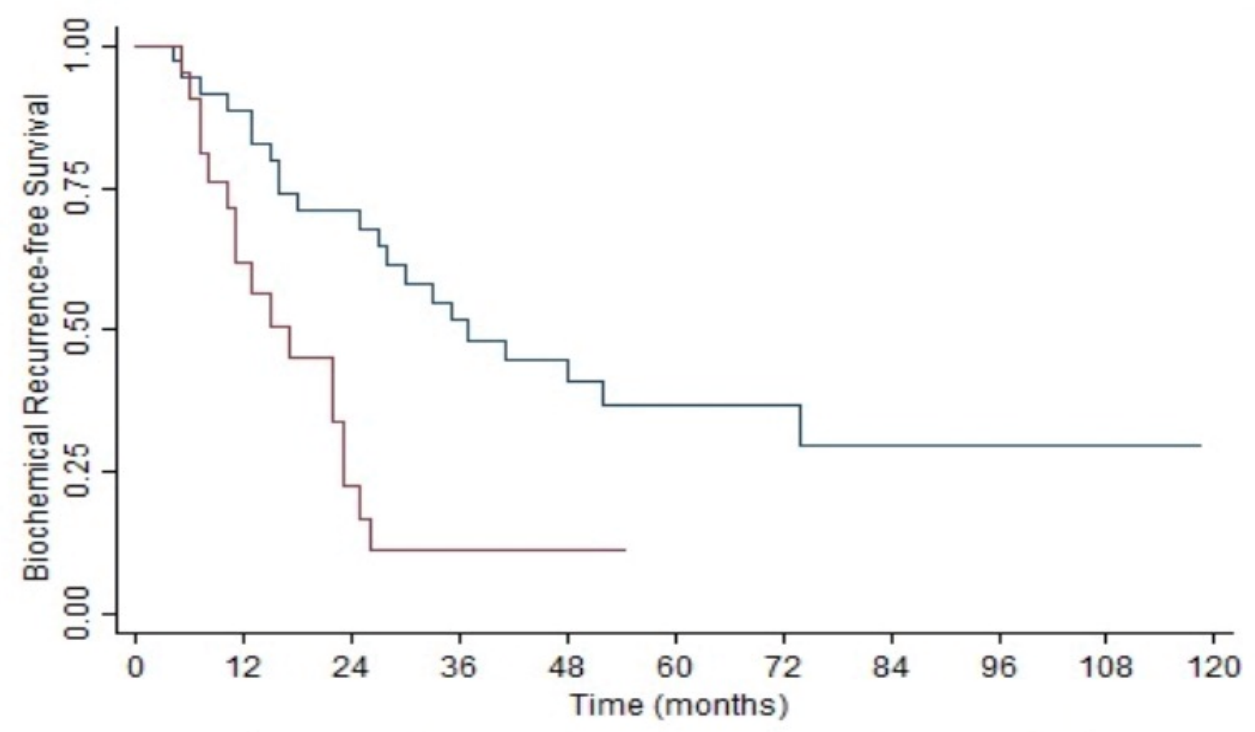

Previous Radiation $\longrightarrow$ Previous Cryo 

Salvage cryotherapy after primary radiation therapy vs. primary cryotherapy

\begin{tabular}{|c|c|c|c|c|}
\hline & Primary rad & lerapy & Primary cryotherapy & $\mathbf{p}$ \\
\hline \multirow[t]{2}{*}{ Number of patients } & 37 & & 21 & \\
\hline & $\begin{array}{c}\text { Brachytherapy } \\
4\end{array}$ & $\begin{array}{c}\text { EBRT } \\
33\end{array}$ & & \\
\hline Mean age & \multicolumn{2}{|c|}{$67.2 \pm 1.0$} & $70.8 \pm 1.4$ & 0.03 \\
\hline $\begin{array}{l}\text { Mean Charlson comorbidity } \\
\text { index }\end{array}$ & \multicolumn{2}{|c|}{$1.1 \pm 0.1$} & $1.4 \pm 0.3$ & NS \\
\hline \multicolumn{3}{|l|}{\begin{tabular}{|l} 
Clinical staging \\
T1a/b \\
T1c \\
T2a \\
T2b \\
T2c \\
T3 \\
Unknown
\end{tabular}} & $\begin{array}{l}0 \\
8 \\
4 \\
5 \\
2 \\
1 \\
1\end{array}$ & NS \\
\hline Mean PSA at time of biopsy & \multicolumn{2}{|c|}{$6.6 \pm 0.6$} & $7.4 \pm 0.7$ & NS \\
\hline $\begin{array}{l}\text { Mean PSA doubling time } \\
\text { (months) }\end{array}$ & \multicolumn{2}{|c|}{$17.1 \pm 1.8$} & $8.5 \pm 1.4$ & 0.002 \\
\hline \multicolumn{3}{|l|}{$\begin{array}{l}\text { Gleason grade } \\
1 \\
2 \\
3 \\
4 \\
5 \\
\text { Unknown }\end{array}$} & $\begin{array}{c}4 \\
4 \\
1 \\
10 \\
2 \\
0\end{array}$ & NS \\
\hline Prostate volume & \multicolumn{2}{|c|}{$26.2 \pm 1.5$} & $28.9 \pm 2.6$ & NS \\
\hline Prostate length & \multicolumn{2}{|c|}{$39.5 \pm 1.2$} & $39.5 \pm 1.7$ & NS \\
\hline Received ADT & \multicolumn{2}{|l|}{7} & 2 & NS \\
\hline
\end{tabular}

ADT: androgen deprivation therapy; EBRT: external beam radiation therapy; NS: not significant. 
Salvage cryotherapy after primary radiation therapy vs. primary cryotherapy

\begin{tabular}{|c|c|c|c|}
\hline & Primary radiotherapy & Primary cryotherapy & $\mathbf{p}$ \\
\hline $\begin{array}{l}\text { Median followup duration } \\
\text { (months) }\end{array}$ & 56.1 & 61.1 & \\
\hline Median PSA nadir & 0.3 & 2.0 & 0.044 \\
\hline $\begin{array}{l}\text { Number of patients to } \mathrm{BCF} \\
\text { (Phoenix criteria) }\end{array}$ & 21 & 17 & 0.001 \\
\hline $\begin{array}{l}\text { Median time to BCF } \\
\text { (months) }\end{array}$ & 18 & 13 & 0.002 \\
\hline $\begin{array}{l}\text { Number of patients with } \\
\text { metastatic progression }\end{array}$ & 7 & 4 & NS \\
\hline $\begin{array}{l}\text { Require further oncological } \\
\text { treatment }\end{array}$ & 14 & 13 & NS \\
\hline $\begin{array}{l}\text { Complications } \\
\text { Total } \\
\text { Bladder neck contracture } \\
\text { Infection } \\
\text { Other }\end{array}$ & $\begin{array}{l}5 \\
4 \\
1\end{array}$ & $\begin{array}{l}3 \\
0 \\
2 \\
1\end{array}$ & \\
\hline
\end{tabular}

BCF: biochemical failure; NS: not significant; PSA: prostate-specific antigen. 


\begin{tabular}{|c|c|c|c|}
\hline & HR & $95 \%$ CI & p \\
\hline $\begin{array}{l}\text { PSA doubling time } \\
\text { (months) }\end{array}$ & 0.94 & $0.90-1.00$ & 0.035 \\
\hline Primary cryotherapy & 2.4 & $1.1-5.4$ & 0.033 \\
\hline
\end{tabular}

CI: confidence interval; HR: hazard ratio; PSA: prostate-specific antigen. 